

\title{
HYBRID PROPULSION FOR LAUNCH VEHICLE BOOSTERS: A PROGRAM STATUS UPDATE
}

\author{
R. L. Carpenter* and T. A. Boardman* \\ Thiokol Corporation \\ Brigham City, Utah \\ S. E. Claflin* \\ Rockwell International Corporation/Rocketdyne Division \\ Canoga Park. California \\ R. J. Harwell \\ NASA/George C. Marshall Space Flight Center \\ Huntsville, Alabama
}

\begin{abstract}
Results obtained in studying the origin and suppression of large-amplitude pressure oscillations in a 24-in.-diameter hybrid motor using a liquid oxygen/hydroxylterminated polybutadiene/polycyclopentadiene propellant system are discussed. Tests conducted with liquid oxygen flow rates varying from 10 to $40 \mathrm{lbm} / \mathrm{sec}$ were designed to gauge the effectiveness of various vaporization chamber flow fields, injector designs, and levels of heat addition in suppressing high-frequency longitudinal mode oscillations. Longitudinal acoustic modes did not arise in any tests. However, initial testing revealed the presence of high-amplitude, sinusoidal, nonacoustic oscillations persisting throughout the burn durations. Analysis showed this to be analogous to chug mode instability in liquid rocket engines brought about by a coupling of motor combustion processes and the liquid oxygen feed system. Analytical models were developed and verified by test data to predict the amplitude and frequency of feed-system-coupled combustion pressure oscillations. Subsequent testing showed that increasing the feed system impedance eliminated the bulk mode instability. This paper documents the work completed to date in performance of the Hybrid Propuision Technology for Launch Vehicle Boosters Program (NAS8-39942) sponsored by NASA's George C. Marshall Space Flight Center.
\end{abstract}

\section{INTRODUCTION}

Since 1992, the ongoing Joint Independent Research and Development Group (JIRAD) has involved the efforts of industry and NASA's Marshall Space Flight Center in the development of hybrid rocket motors. A main finding of JRAD is that under some conditions hybrid motors exhibit pressure oscillations. While the oscillations are not unstable in the sense of increasing amplitude, in worst-case conditions they have spiked to double the motor operating pressure.

In 1993, NASA solicited proposals for a program to develop an engineering data base for hybrid propulsion technology. The scope of the effort was to cost approximately $\$ 40$ million. Thiokol Corporation, Space Operations, and Martin Marietta Corporation, who had been notified of the intent to negotiate the program, had been working together with NASA to provide a coordinated effort. Funding problems developed before the contracts for the planned programs were awarded, causing the Thiokol and Martin Marietta efforts to be significantly reduced. Subsequently, Thiokol's work was redirected toward gaining an understanding of the pressure oscillations that had been observed during the JIRAD program.

At this time, Lockheed Martin Corporation and Rockwell International Corporation. Rocketdyne Division, participate as stibcontractors to Thiokol, and MSFC provides test facilities and test support. The Hybrid Propulsion for Launch Vehicle Booster Program's contracting office technical representative is Mr. Roger Harwell of MSFC.

Approximately 75 percent of the work on the program has been completed. This paper serves as an interim report on the program. Upon completion of the program, test configurations. data, and discussions will be put into a CD-ROM format that can be ordered from MSFC.

\footnotetext{
* Member. AIAA

Copyright (C) 1995 by the American Institute of Aeronautics and Astronautics, Inc. All rights reserved.
} 


\section{BACKGROUND}

A significant body of research has been devoted to the problem of flame stabilization in ramjets. Two factors that affect flame stabilization are the temperature of incoming gas and the flow field at the entrance to the fuel grain. Because of the similarity of hybrids and ramjets. it is reasonable to assume the same factors will affect flame stability in hybrids. Based on this hypothesis. ${ }^{1}$ an IRAD program was initiated by MSFC and Rocketdyne to investigate the effects of head-end flow fields on hybrid combustion in a gaseous-oxygen-fed hybrid motor. Results from the IRAD program support the hypothesis that flame holding recirculation zones in the head end of the motor can be used to achieve smooth combustion.

Eariy results from the IRAD program and the ramjet research provided the basic hypothesis for this program, i.e., flame stabilization at the entrance to the fuel grain is required for smooth hybrid motor combustion. This program investigates the effects of liquid oxygen flow rates, head-end flow fields, and liquid oxygen vaporization on hybrid pressure oscillations. Each of these factors is thought to directly affect the establishment of a stable flame at the entrance of a fuel grain port.

\section{APPROACH}

The program makes use of two different hybrid motors for testing: an 11-in. motor and a 24-in. motor. (These measurements refer to the external case diameters of the motors.) The 11-in. motor is used with both gaseous oxygen and liquid oxygen feed systems for the purpose of separating liquid oxygen vaporization from other param- eters with respect to pressure oscillations. The 24 in. motor is used only with a liquid oxygen feed system.

To date. all program effort has used the 24 in. motor. The 11-in. motor was used during the aforementioned IRAD program; an added scope of effort on the present program will extend the 11 -in. motor IRAD with both gaseous oxygen and liquid oxygen testing. As the $11-$ in. motor work has not been started, its results will be included in the final report for the program. This paper discusses only the work on the 24-in. motor.

All testing to date has used a hydroxl-terminated polybutadiene (HTPB) fuel with the following approximate formulation:

$$
\begin{aligned}
& \text { R45HT polymer .......44 percent } \\
& \text { Isophorone diisocyanate . . .5 percent } \\
& \text { Escorez }^{\mathrm{TM}} \ldots \ldots \ldots \ldots \ldots \text { percent } \\
& \text { Voranol }{ }^{\circledR} \text { and Elftex ....... } 1 \text { percent }
\end{aligned}
$$

Both the 11-in. and the 24-in. motors can be assembled with several configurations. Variations of each motor include the following parameters: forward plenum, grain length, aft mixing chamber, port geometry, and injector.

The major case components of the 24-in. motor (Figure 1) comprise the forward closure, vaporization chamber, grain sections, mixing chamber, and aft closure. As with the 11-in. motor, the 24-in. motor is designed to enable the lengths and configurations of each of its components to be varied. For example, it has been tested with grain lengths of from 54 to 324 inches.

Both the main fuel grains and the fuel in the vaporization chamber can be case bonded or cartridge

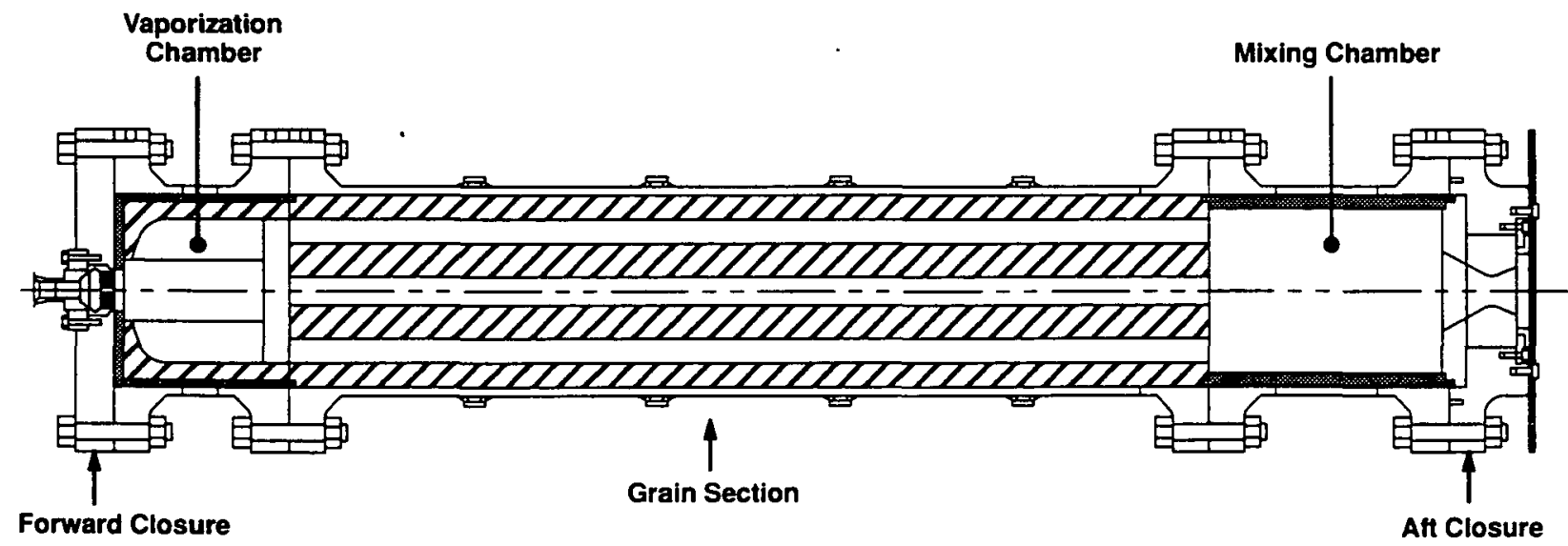

Figure 1. 24-Inch Motor Configuration

1 T. A. Boardman. D. H. Brinton. R. L. Carpenter. and T. F. Zoladz. “An Experimental Investigation of Pressure Oscillations and Their Suppression in Subscale Hybrid Rocket Motors." AlAA Paper No. 95-2689, 31st AIAA/ASME/SAE/ASEE Joint Propulsion Conference and Exhibit, July 1995. 
loaded. For this program. the main fuel grains are case bonded and the vaporization chamber is cartridge loaded. Typically, a fuel grain is used for several tests and the vaporization chamber fuel configuration is changed between tests to alter flow patterns or heat available for liquid oxygen vaporization.

For this program, all 24 in. motor tests use identical. monolithic, 108-in.-long. seven-port, fuel grains. A typical test duration is $10 \mathrm{sec}$. To reduce costs, the same fuel grain is used for several tests. Multiple use of the same fuel grain introduces a variable into the testing since as the ports burn out their cross-sectional area increases. At any fixed rate of liquid oxygen flow, the increasing port area decreases flux through the port. Thus, if two tests using the same fuel grain are conducted at $20 \mathrm{lb} / \mathrm{sec}$ of liquid oxygen flow, the second test will have a lower flux than the first. This change of flux in the port is not ideal, but the cost of using a new grain for every test would exceed the available funding.

Planned variations for the vaporization chamber include the following five fuel configurations:

- Dome-shaped fuel with no fins (NF)

- Domed with six fuel fins running the length of the vaporization chamber $(F)$

- Domed with six fuel fins that are shortened so they can be rotated $30 \mathrm{deg}$ to a position in front of the fuel grain ports (FR)

- Domed with fins and double length to provide twice the fuel surface area for the vaporization of liquid oxygen. The doublelength configuration can be used in either the baseline position (LF) or with the fins rotated $30 \mathrm{deg}$ to a position in front of the ports (LFR)

Note that the abbreviations in parentheses after each of the above vaporization chamber fuel configurations are used hereafter to refer to the configuration. For example: NF means no fins: $F$ is fins; FR is fins rotated 30 deg; LF, long (double-length) fins; and LFR. long fins rotated $30 \mathrm{deg}$. These vaporization chamber fuel configurations are illustrated in Figure 2.

The program makes use of six different LOX injectors: three axial-flow injectors and three wide-flow injectors. For each of the two flow patterns. there are injectors for liquid oxygen flow rates of 10,20, and 40 $\mathrm{lb} / \mathrm{sec}$. The injectors are designed so that approximately the same pressure drop occurs across any injector when it is operating at its designed flow rate. The following abbreviations are used to identify the six injectors.

\begin{tabular}{ccc}
\hline $\begin{array}{c}\text { Targeted } \\
\text { Flow Rate } \\
\text { (lb/sec) }\end{array}$ & $\begin{array}{c}\text { Axial Flow } \\
\text { Pattern }\end{array}$ & $\begin{array}{c}\text { Wide Flow } \\
\text { Pattem }\end{array}$ \\
\hline 10 & AL (axial, low) & WL (wide, low) \\
20 & AM (axial, medium) & WM (wide, medium) \\
40 & AH (axial, high) & WH (wide, high) \\
\hline
\end{tabular}

Injector flow pattern is a major factor in determining the flow field in the head end of the motor. Previous testing with axial-and wide-flow injectors has produced dramatic differences in combustion smoothness. Wideflow injectors appear to be the more desirable choice for flight motors; a program goal is to verify this by obtaining a comparison of the two injector types with respect to their effects on combustion smoothness for different vaporization chamber configurations. The two injector flow pattems, axial and wide flow, are shown in Figure 3.

The liquid oxygen feed system for the 24-in. motor, the feed system configuration used for the first six tests, is shown in Figure 4. After the sixth test, a change was made to increase isolation between the feed system and the motor. This change and the reasons for it are discussed later in this paper.

The feed system is designed with two legs that can be turned off and on during a test to provide three separate venturi-controlled flow rates to the motor. Flow can also be controlled by the electrohydraulic valve that is upstream from the motor. Bleed valves are used to enable most of the feed system to be chilled prior to a test. A nitrogen purge is used to empty the feed system of liquid oxygen downstream of the electrohydraulic valve during shutdown. and to prevent backflow through the injector.

The approach to testing used on the 24-in. motor is outcome based. For each test, the motor configuration and test conditions for each test are determined by the results of previous tests. There is no fixed matrix of tests that are to be performed. The logic is designed to gain an understanding that will enable the design of hybrid motors which operate smoothly at flux levels optimized for the intended application.

The test logic starts with a test at a low flow rate, an axial injector, and a no-fin vaporization chamber fuel configuration. If a test condition produces pressure oscillations of unacceptable magnitude, the fuel configuration in the vaporization chamber is then changed to provide increased heat input or a flow field that may increase flame stabilization. If a test condition produces acceptably smooth combustion, the logic then moves to increase flow rate, while keeping the vaporization fuel 
CONFIGURATION NF

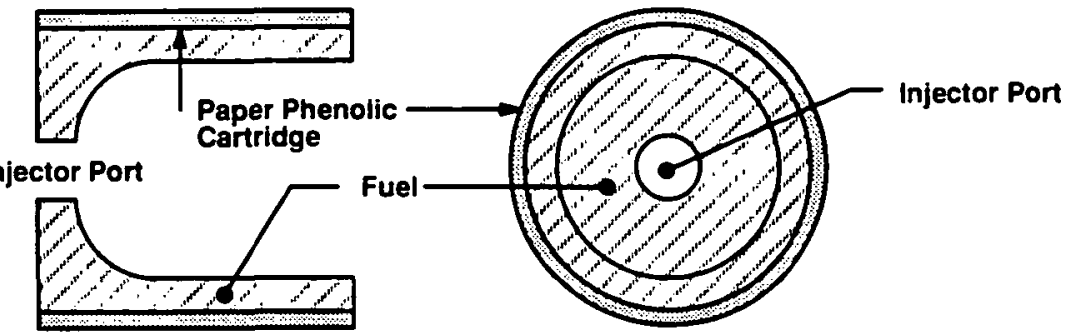

CONFIGURATION F

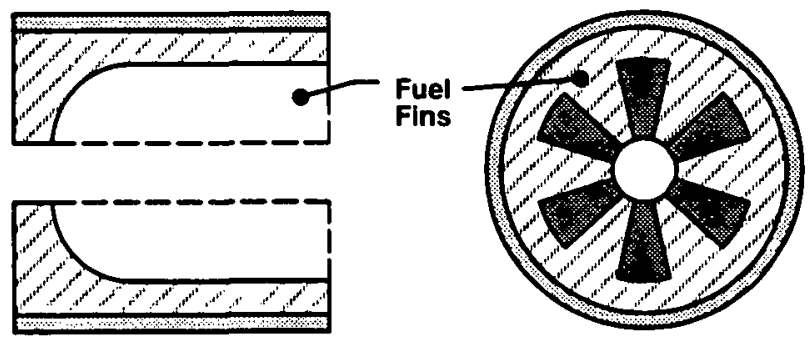

CONFIGURATION FR

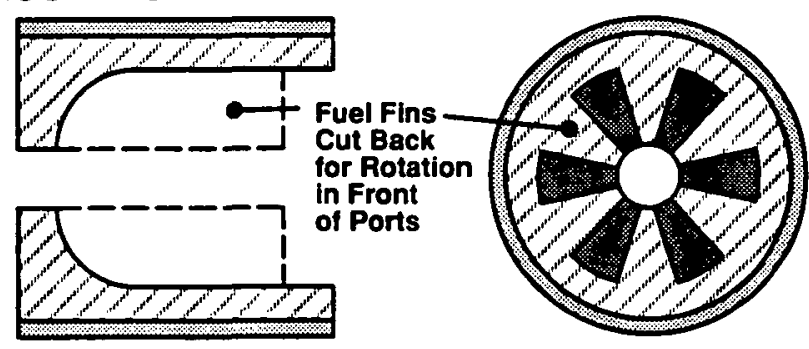

CONFIGURATION FL
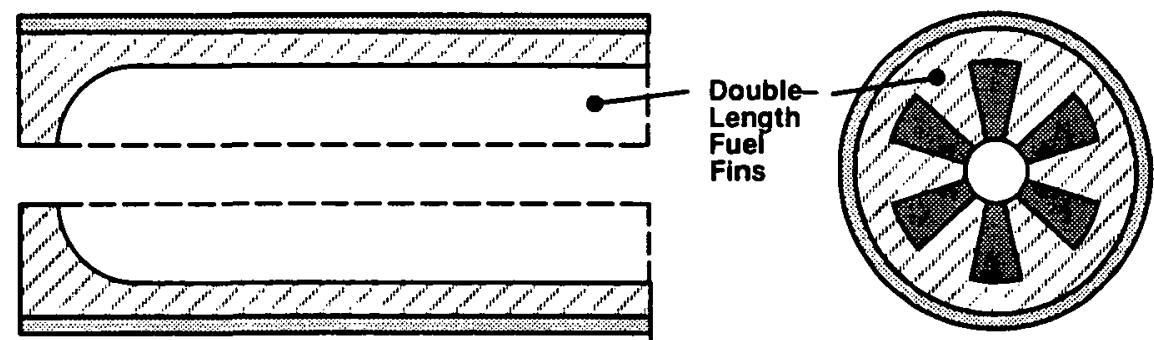

CONFIGURATION FRL

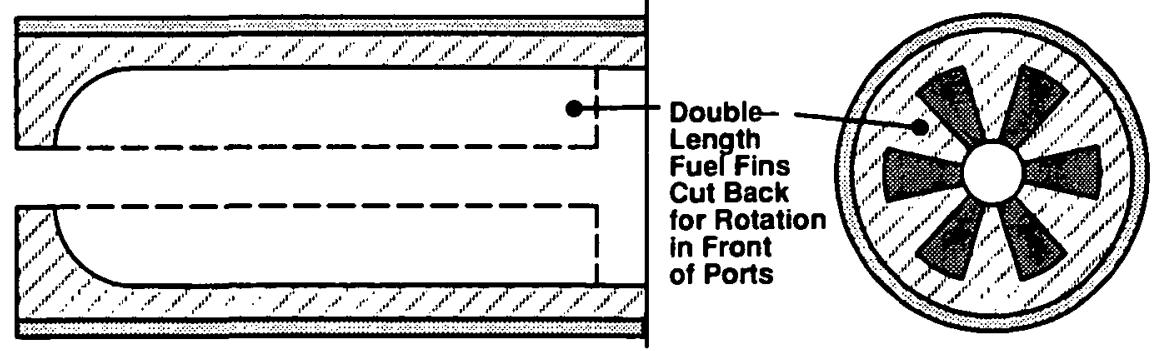

Figure 2. Vaporization Chamber Fuel Configurations 


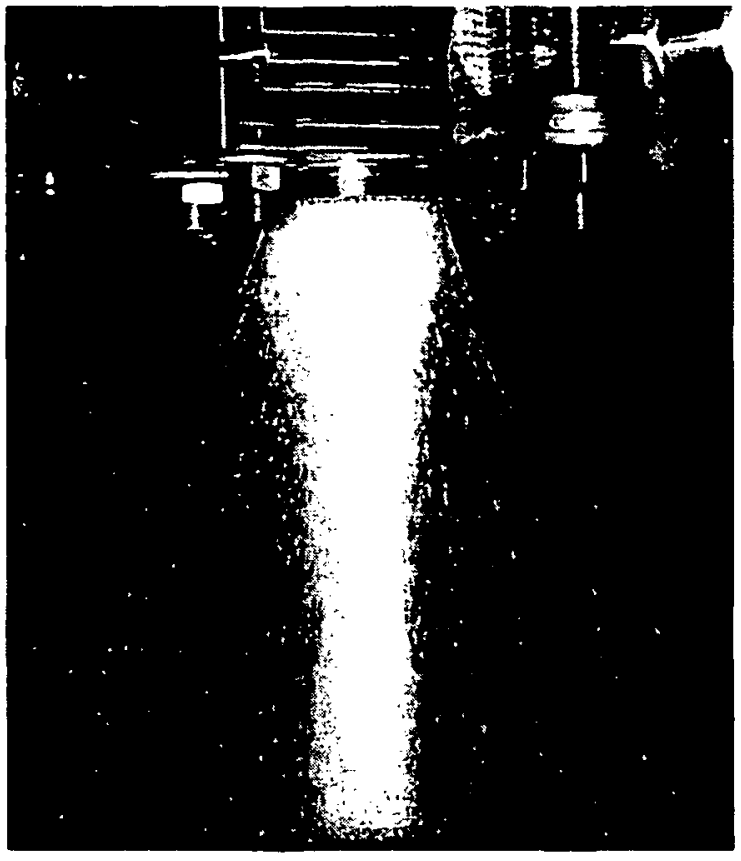

Axial Flow

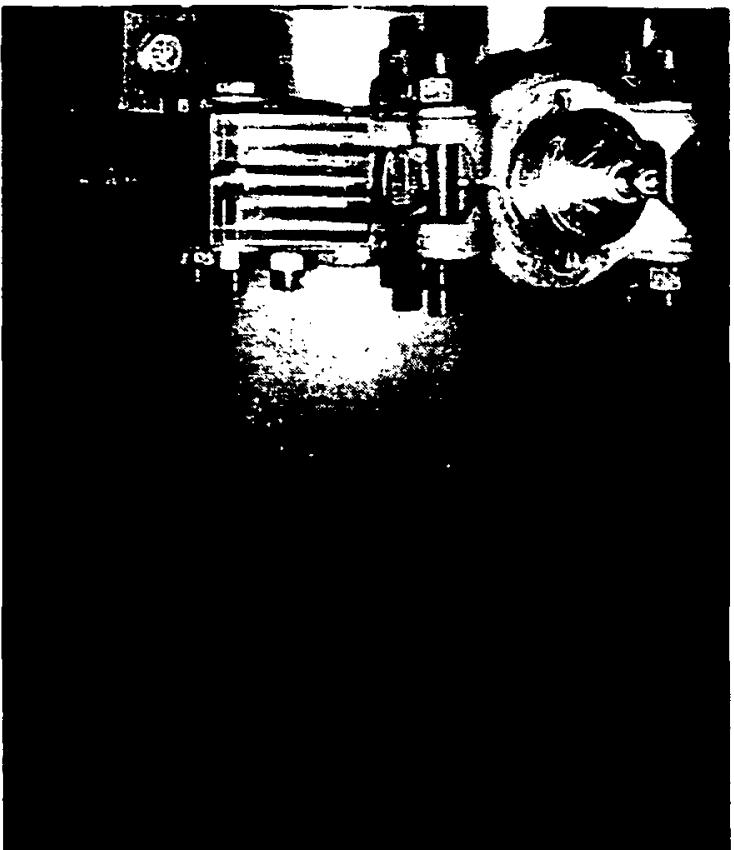

Wide Flow

Figure 3. 24-Inch Motor Injector Flow Patterns

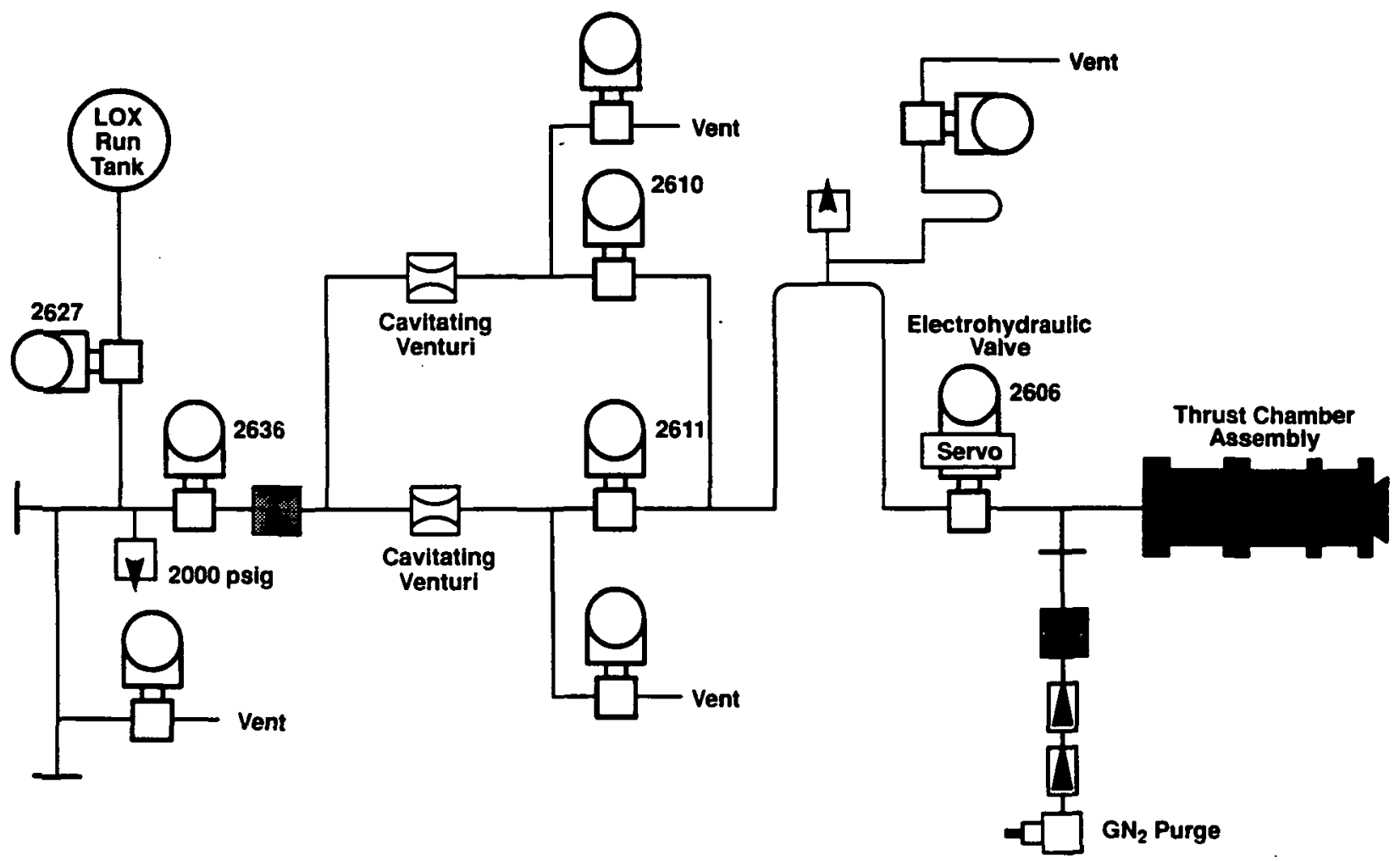

Figure 4. 24-Inch Motor LOX Feed System 
configuration the same. The initial tests are conducted with axial-flow injectors and a second series with wide-flow injectors.

The program test logic for the 24-in. motor is shown in Figure 5. Each block in Figure 5 contains information concerning the test represented by the block. The test number relative to the logic diagram is on the top, left corner of the block. The first entry defines the injector using the abbreviations given earlier. e.g., $\mathrm{AL}$ for axial low flow. The second entry, the fuel configuration for the vaporization chamber, is identified by an abbreviation. e.g., NF for no fins. The last entry is the flow rate for the test. (The flow rate entry is somewhat redundant as it can be surmised from the injector.) All tests were targeted for $500 \mathrm{psi}$. The nozzle throat diameter is changed before each test to keep the pressure constant. While it is recognized that changing the throat size will change $L^{*}$. a parameter of ten associated with pressure oscillations. all tests were conducted at a constant pressure in order to eliminate pressure as a variable.

In the paragraphs that follow, the tests are referred to both by their position in the test logic diagram and by the chronological order in which they were performed. When referring to a test's position in the logic diagram. the " $L$ " number from the logic diagram is used. For example, $\mathrm{L}-1$ is the first test on the logic diagram. The chronological position of a test is specified as a number without any prefix. That is, although Test 2 is the second test that was performed. it appears as test L-5 on the logic diagram of Figure 5. The shaded blocks on Figure 5 are motor configurations that have either been tested or are planned for use during the remainder of the program. The test numbers above the blocks indicate the chronological order in which the variable conditions were tested.

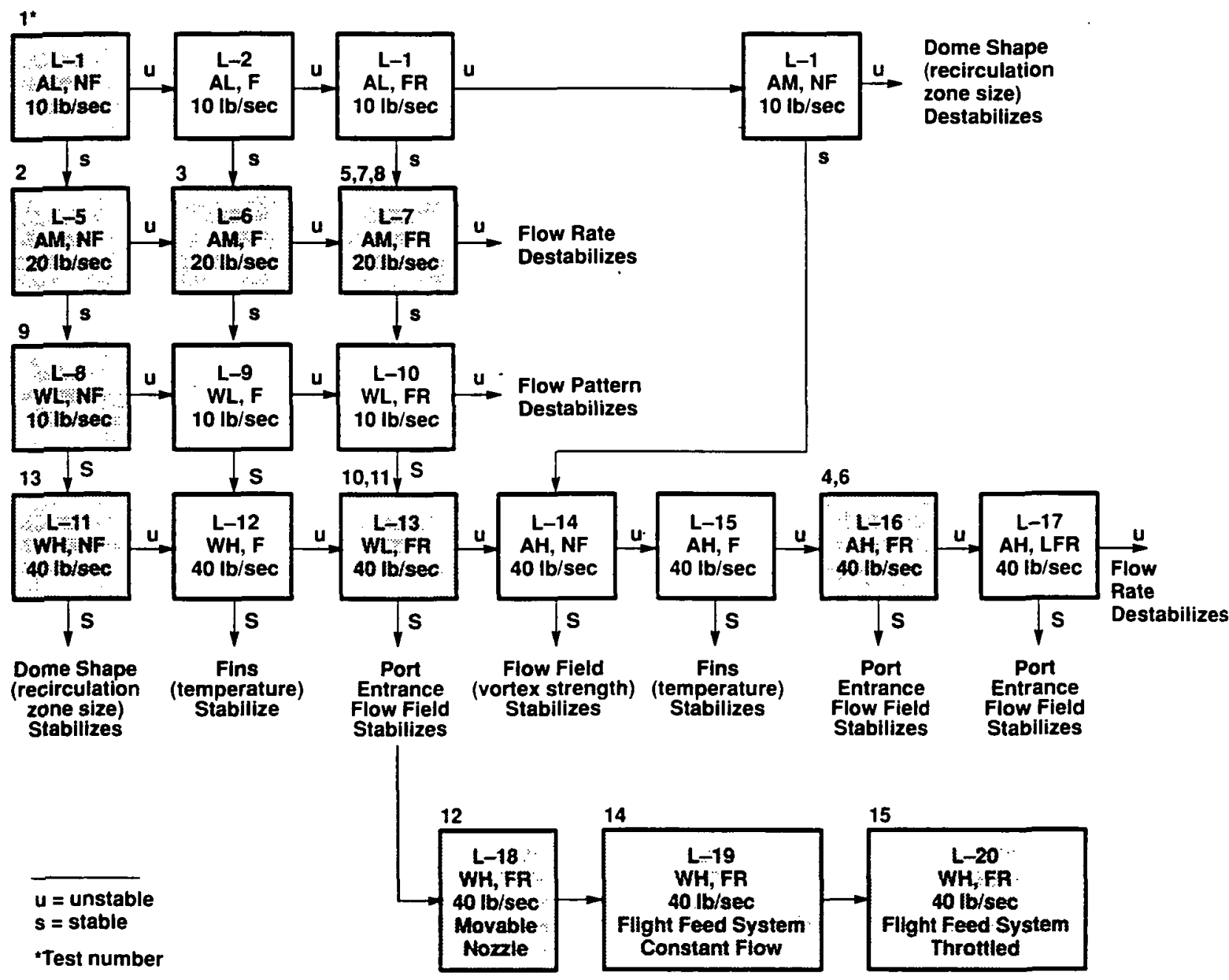

Figure 5. 24-Inch Motor Test Logic 


\section{TEST RESULTS}

Tests 1 Through 12

The first test that was run on the program used the lowest flow rate $(10 \mathrm{lb} / \mathrm{sec})$ and a dome-shaped vaporization chamber with no fuel fins (Test L-1 in Figure 5). This is the head-end fuel configuration that provides the minimum surface area and. consequently, the least heat for vaporizing liquid oxygen. The injector pattem was axial. This configuration is illustrated in Figure 6. which also shows the pressure trace that was obtained from the test. This motor configuration and test conditions produced smooth combustion, as shown by the pressure trace in Figure 6.

Since the first test produced smooth combustion. the liquid oxygen flow was doubled to $20 \mathrm{lb} / \mathrm{sec}$ for the second test. The injector pattern and the fuel configuration in the vaporization chamber were left unchanged (Test L-5 in Figure 5). The second test produced pressure oscillations with average amplitudes that were 22 percent of the chamber pressure.

Following the test logic. the next test kept the flow constant at $20 \mathrm{lb} / \mathrm{sec}$ and added fins to the vaporization chamber (Test $L-6$ in Figure 5). This test produced pressure oscillations similar to those of the previous test at $20 \mathrm{lb} / \mathrm{sec}$. Figure 7 shows the motor configuration and pressure trace for Test $\mathrm{L}-3$.

Adding fins to the vaporization chamber did not decrease the pressure oscillations: therefore, the next test was planned to again flow $20 \mathrm{lb} / \mathrm{sec}$, with the fins rotated $30 \mathrm{deg}$ to a position in front of the fuel grain ports (Test L-7 configuration and test conditions). Although the motor was set in the test stand with this configuration, due to an error, both legs of the feed system were opened and liquid oxygen flowed at $40 \mathrm{lb} / \mathrm{sec}$ instead of the $20 \mathrm{lb} / \mathrm{sec}$ that was planned. Thus, the actual test conditions were closer to $\mathrm{L}-16$ than to $\mathrm{L}-7$. The difference from Test L-16 was that a medium-flow axial injector was in the motor instead of the high-flow axial injector called for in

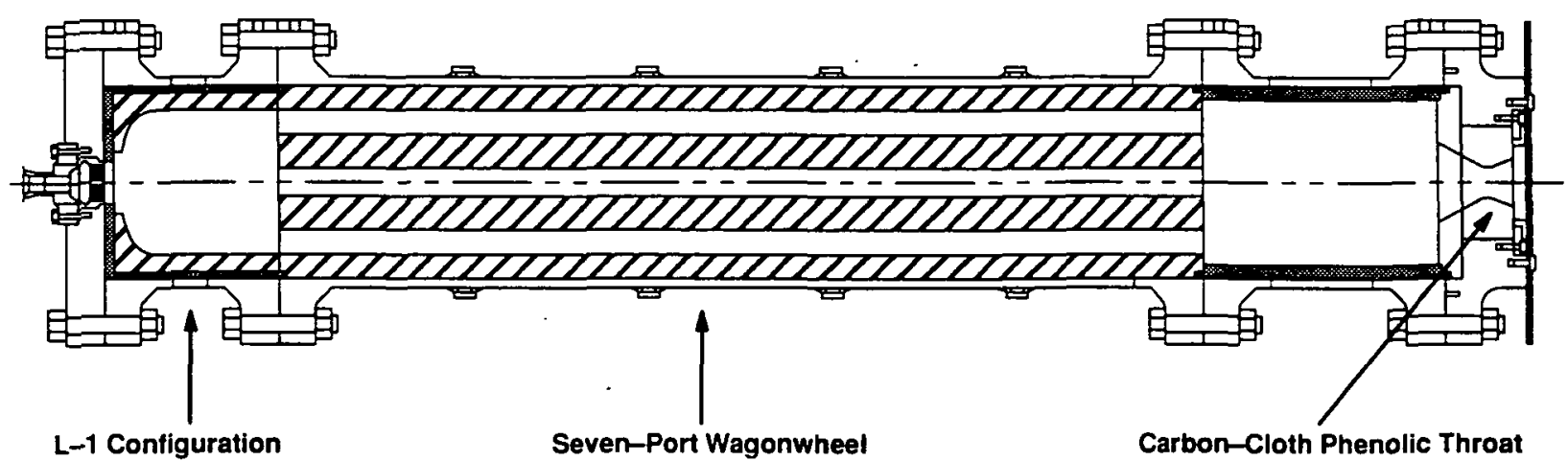

$L-1$ Configuration

Seven-Port Wagonwheel

- NF, domed center perforated

- AL injector

\section{HTPB Escorez Fuel}

Carbon-Cloth Phenolic Throat

- $D_{1}=2.55$ in.

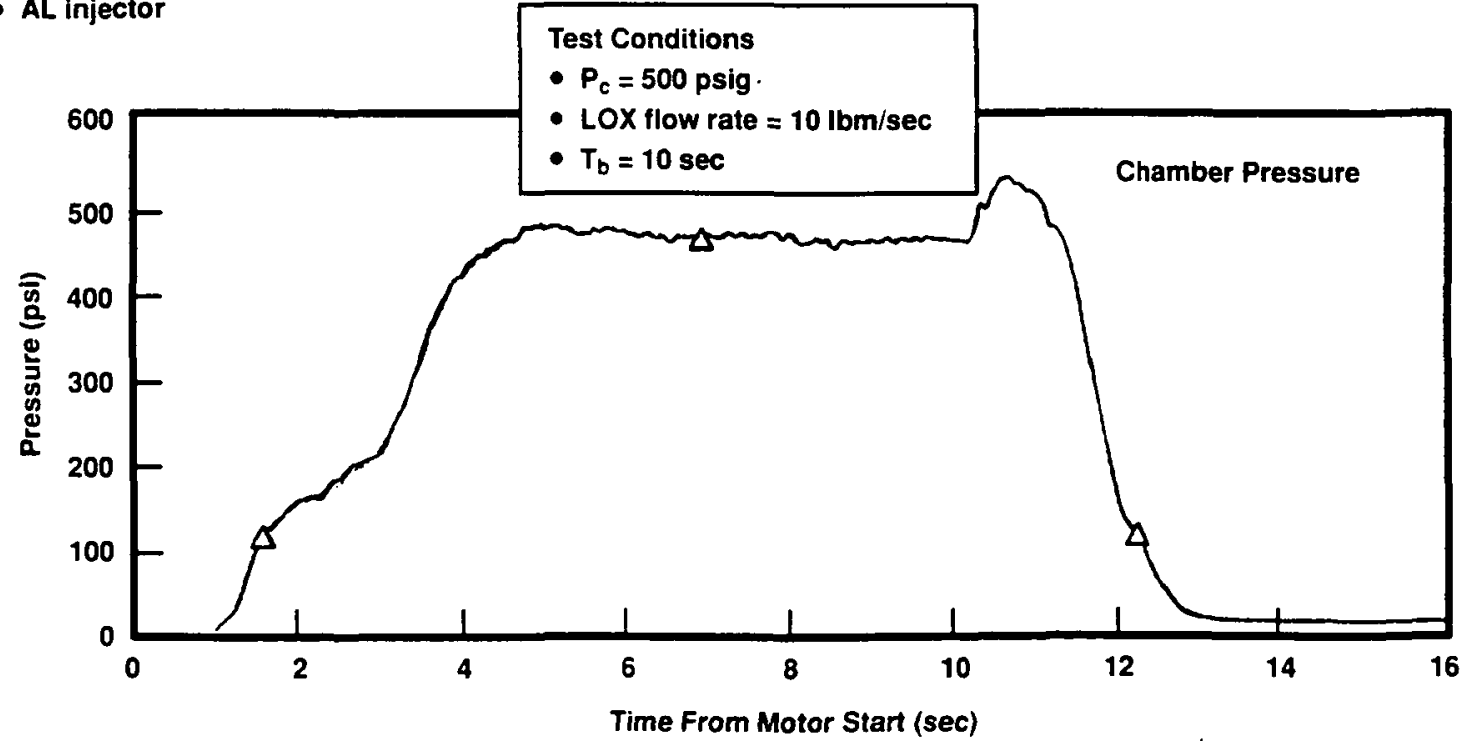

Figure 6. Test 1 Motor Configuration and Pressure Trace 




Figure 7. Test 3 Motor Configuration and Pressure Trace

configuration L-16. Surprisingly, the higher flow conditions gave much reduced pressure oscillations.

Since both the fin configuration and, inadvertently, the liquid oxygen flow had been changed, it was not clear which was responsible for the reduced amplitude of the pressure oscillations. The test was repeated with the originally planned flow of $20 \mathrm{lb} / \mathrm{sec}$ and the fins in the rotated position (Test $\mathrm{L}-7$ ). This test produced oscillations very similar to the previous $20-\mathrm{lb} / \mathrm{sec}$ tests. Thus, it appeared that none of the tested vaporization chamber configurations had a significant effect on the pressure oscillations. However, increasing the flow rate to 40 $\mathrm{lb} / \mathrm{sec}$ caused a dramatic decrease in the amplitude of the oscillations.

Because of the unanticipated smooth combustion that was obtained with Test 4, the motor was tested again with the same configuration and with both legs of the feed system flowing to make certain the result was repeatable. This second test produced an almost identical pressure trace to that of Test 4 . The motor configuration and pressure trace for this test are shown in Figure 8.

At this point a temporary pause was made in the testing to analyze data and revisit the test logic. The program participants pursued varied hypotheses concerning the pressure oscillations. Rocketdyne performed a dynamic analysis that treated the thrust chamber assembly and feed system as coupled components. (A schematic for the Rocketdyne analysis is shown in Figure 9.) Using their best estimates for component parameters, they concluded the feed system was a significant factor in the oscillations and that the thrust chamber assembly and feed system interacted through a combination of feed system softness and vaporization lag in the thrust chamber.

An assumption made in setting up the program initially was that the facility feed system would provide liquid oxygen at a constant flow rate, independent of conditions in the motor. An intended consequence of this assumption was that the hybrid thrust chamber could be 


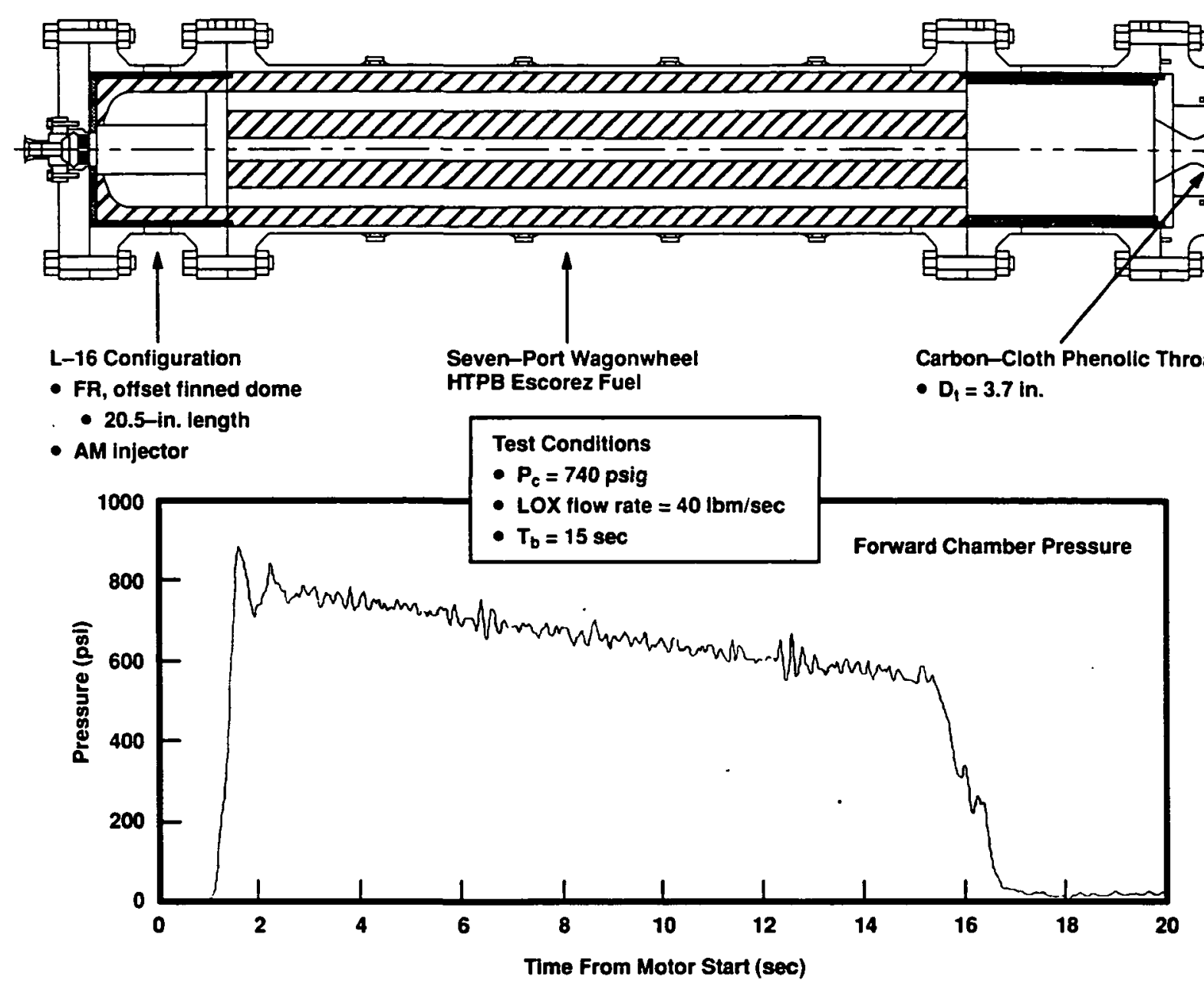

Figure 8. Test 6 Motor Configuration and Pressure Trace

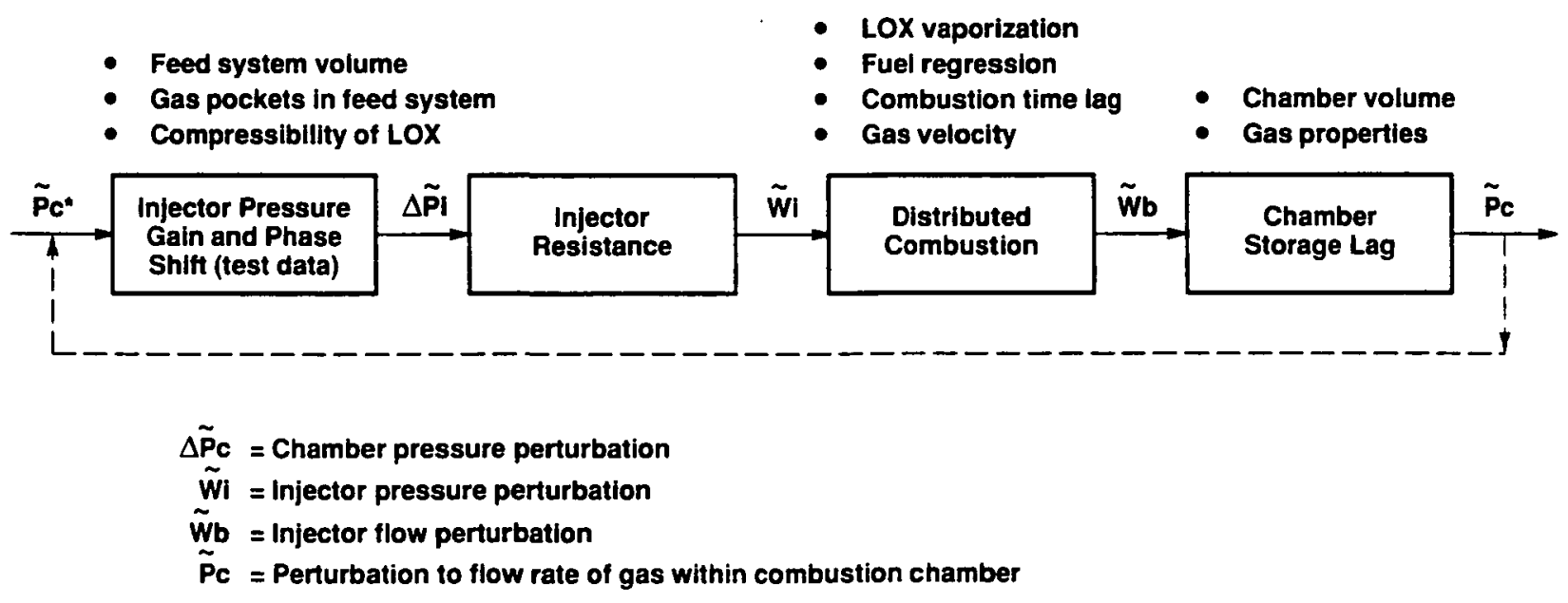

Figure 9. Control Loop Analysis of 24-Inch Motor 
considered independently of the feed system for the purpose of studying motor pressure oscillations. The Rocketdyne conclusion was in conflict with the assumption that the thrust chamber assembly processes could be studied independently. If the Rocketdyne hypothesis was correct, interaction with the feed system was a major factor in the pressure oscillations.

To test the coupled feed system hypothesis, an orifice was placed in the feed system as close to the injector as possible. Placing the orifice near the injector effectively increased the hydraulic resistance of the injector without affecting the injection velocity and, thus, the vaporization. In this way, the characteristics of the feed system were changed without any change in the thrust chamber characteristics. The location of the orifice is shown in Figure 10. The orifice was sized to provide a pressure drop of $250 \mathrm{psi}$ at a flow of $20 \mathrm{lb} / \mathrm{sec}$. With this pressure drop, the calculated gain between motor and feed system was reduced fivefold. If feed system coupling was a major factor in the pressure oscillations, this reduction in gain should significantly reduce their amplitude.

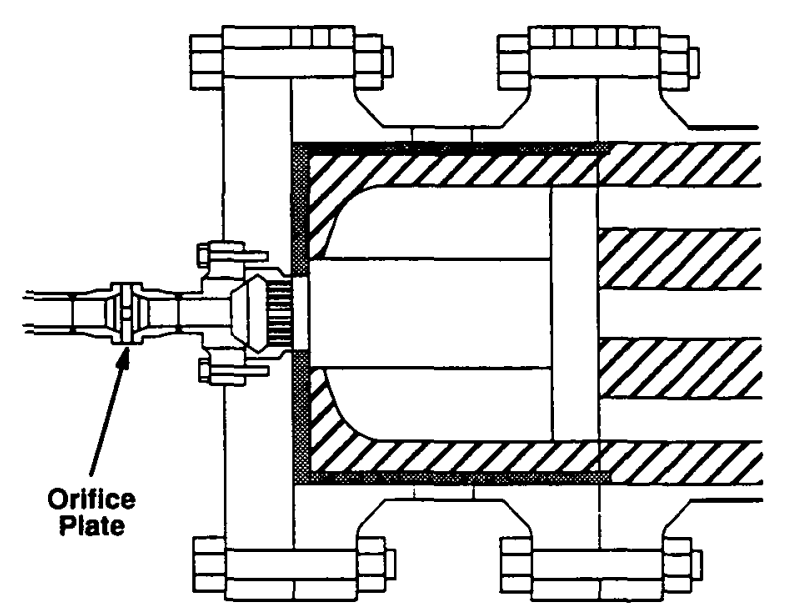

Figure 10. Orifice Location in Feed System

Test 5 (L-7), which produced oscillations with amplitudes of approximately 32 percent of mean pressure, was repeated with the orifice in the feed system. With this orifice location, the average amplitude was reduced to approximately 7 percent of mean pressure. confirming the Rocketdyne hypothesis.

Following the orifice test, the program team decided to add a cavitating venturi to the feed system for the remainder of the tests. The venturi is located upstream of the injector in place of the orifice. The venturi is changed between tests, as required, to provide the necessary flow condition of 10,20 , or $40 \mathrm{lb} / \mathrm{sec}$ of liquid oxygen. The intent of the venturi is to provide a high degree of isolation between the feed system and the motor in order to conduct tests that would closely approximate the originally assumed conditions of thrust chamber and feed system independence.

The injector used on Tests 4 and 6 . the two $40-\mathrm{lb} / \mathrm{sec}$ liquid oxygen tests, had not been planned for use with flow rates as high as $40 \mathrm{lb} / \mathrm{sec}$. Consequently, the pressure drop across the injector was higher than had been planned for, or experienced on, previous tests. A review of data from the first six tests shows that the tests at $10 \mathrm{lb} / \mathrm{sec}$ (Test 1) and at $40 \mathrm{lb} / \mathrm{sec}$ (Tests 4 and 6), which had essentially smooth combustion, also had higher pressure drops across the injector than the tests at $20 \mathrm{lb} / \mathrm{sec}$ (Tests 2,3 , and 5) that had oscillated. This observation on injector pressure drops supports the coupled feed system hypothesis. For the tests with smooth combustion, the injector was providing a higher degree of feed system isolation than on the oscillatory tests.

Subsequent to the Rocketdyne analysis and the tests which suggested the feed system and thrust chamber were coupling to produce oscillatory behavior, Thiokol developed a simulation model to study this oscillatory mode further. This model was created specifically to determine the conditions under which the feed system and combustion chamber would couple in a low-frequency, bulk mode (nonacoustic) oscillation. The simulation model was created using MATRIXx Xmath software. The model was restricted to mechanisms that were thought to cause or affect the feed system/combustion chamber coupling. It was reasoned that this coupling would require an out-of-phase relationship between the feed system pressure and the combustion chamber response pressure. Figure 11 depicts a schematic diagram of the basic elements that were modeled. This nonlinear model showed that an additional phase shift mechanism was required between the feed system and the combustion chamber to cause any oscillatory behavior between the feed system and the combustion chamber. After studying past work on liquid rocket engines, it was determined that a time delay was associated with the vaporization of the liquid oxygen droplets being injected into the chamber and the generation of pressure associated with the combustion of the vaporized oxidizer. When this vaporization time delay was included, the model produced oscillations of the same frequency and magnitude as those seen in the tests. This match can be seen in Figure 12.

To understand the stability boundaries of the system, a linearized model was created (Figure 13). With this model. the important physical parameters that govern the 


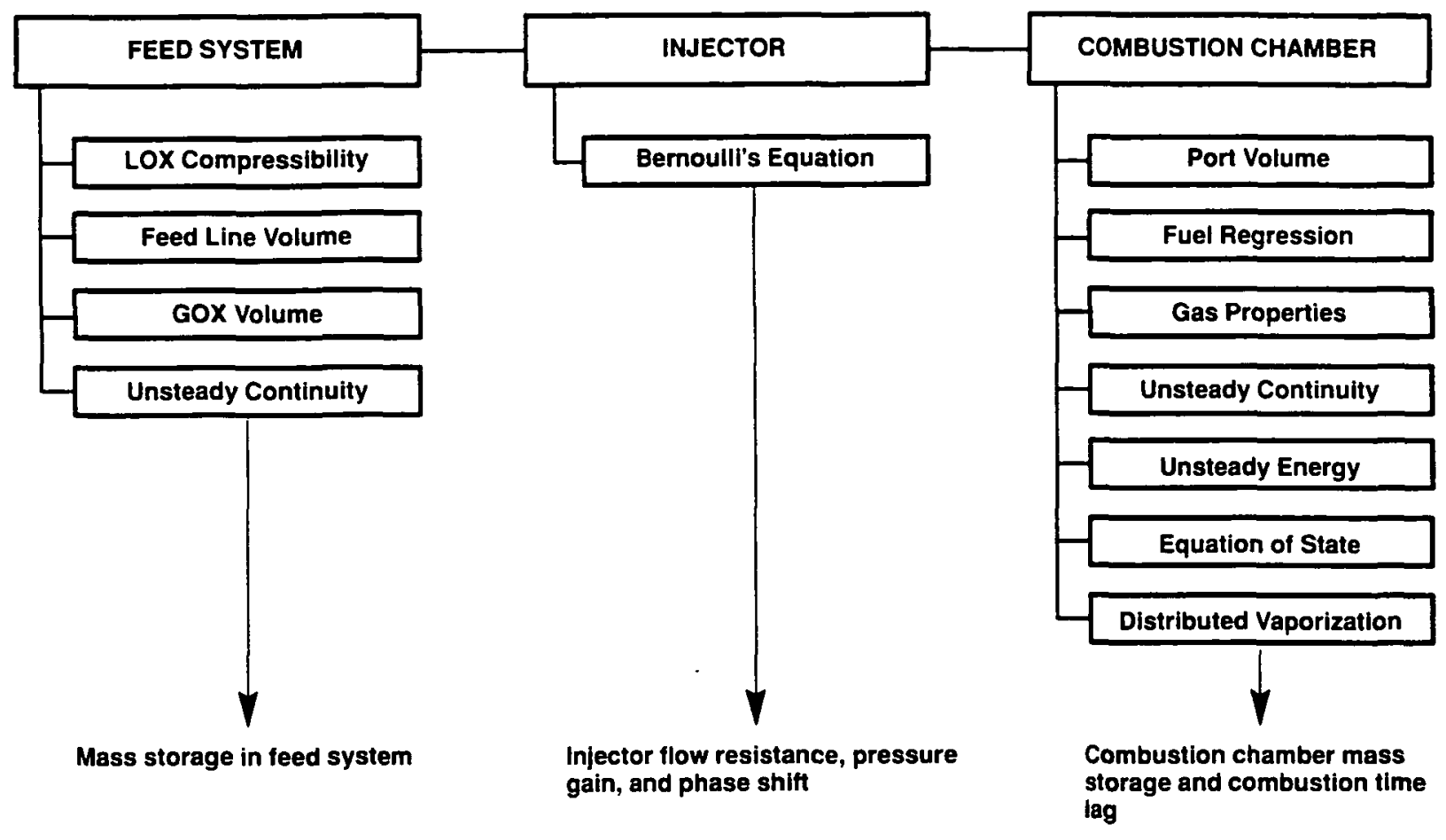

Figure 11. Hybrid Motor System Dynamic Nonlinear Model

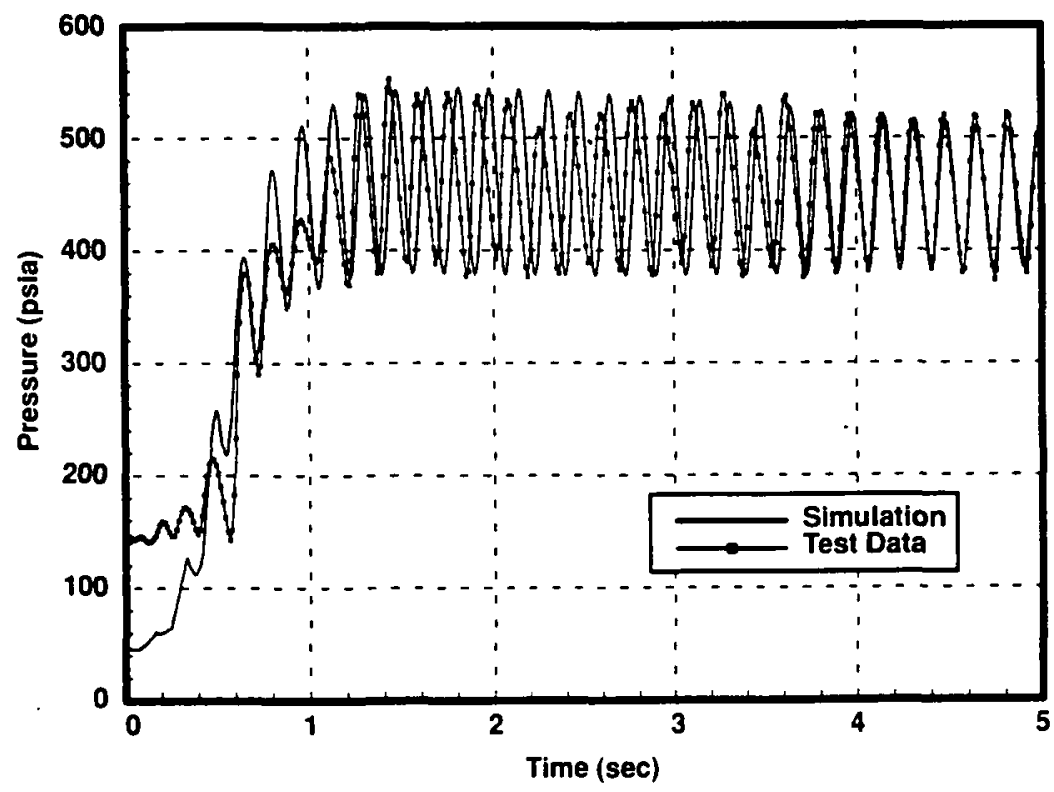

Notes:

- Test data from 24-in. IRAD

Test 2023005, Feb 15, 1995

- Baseline simulation data: LOX flow rate $=20 \mathrm{lbm} / \mathrm{sec}$ Injector cda $=0.5$ in. $^{2}$

- Vaporization parameters: Vaporization/combustion delay $=0.08$ sec

Flow split $=0.185$

- Feed system parameters: Liquid bulk modulus $=11,500 \mathrm{psi}$ Volume $=1235$ In. $^{3}$

Gas free volume $=50$ in. $^{3}$

Figure 12. Chamber Pressure Comparison of Simulation Versus Test Data

characteristic response of the system were determined. These system parameters $\left(\mathrm{K}_{1}, \mathrm{~K}_{2} ; \mathrm{K}_{3} / \mathrm{K}_{5} ; \mathrm{K}_{4}, \mathrm{~K}_{5} ;\right.$ and $\left.\mathrm{K}_{1}\right)$ all have defining equations that relate them to test hardware geometry, fluid properties. and fuel properties which are not discussed here. Using the linearized model, it was possible to define the conditions under which the feed system coupling instability would occur.

Using the best estimates for feed system parameters (more exact parameters were not known) and known 

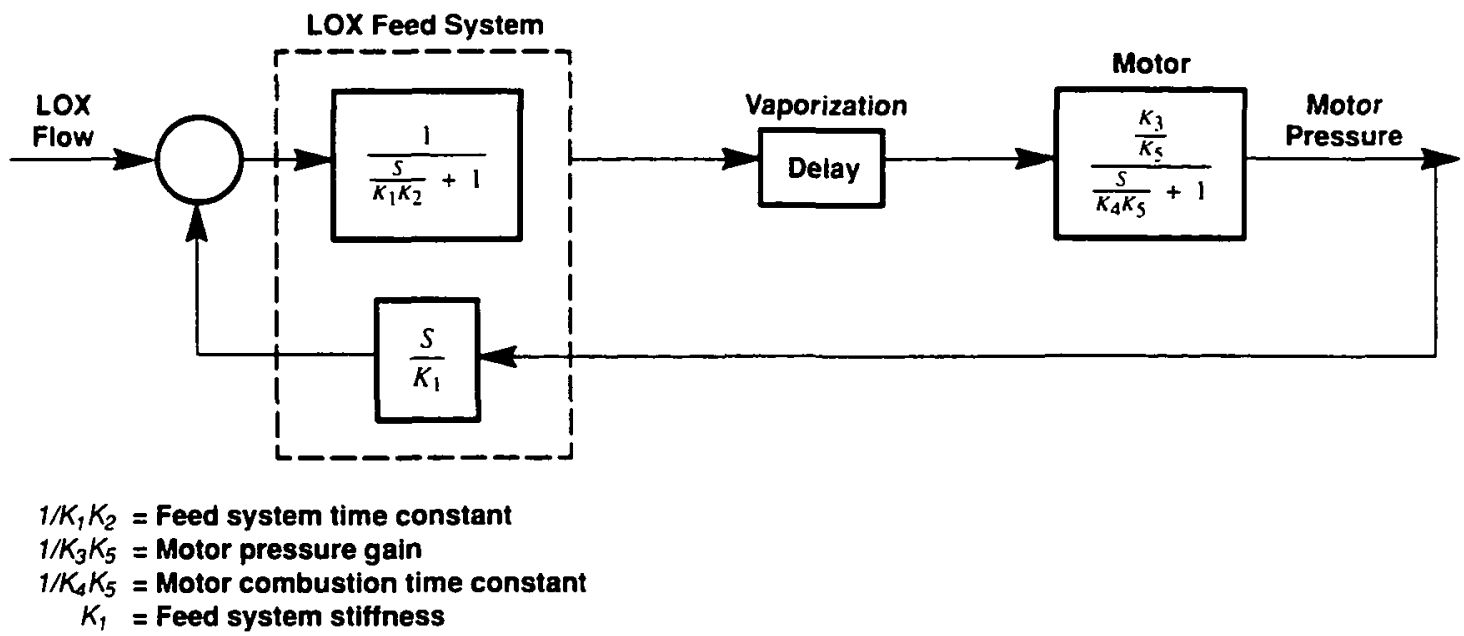

Figure 13. Equivalent Linear Model

motor parameters, the model does well in predicting both the frequency and the amplitude of the observed oscillations. The model shows that two conditions must exist to produce these oscillations: 1) A soft feed system (i.e.. having mass storage variability with time), and 2) oxygen vaporization/combustion delay or time lag. If either of these mechanisms is missing, the system cannot produce enough phase shift to couple the feed system and the combustion chamber in an out-of-phase, classic instability, operating mode. In addition. it was found that increasing the injector pressure drop could also greatly dampen or eliminate the oscillations.

Testing With an Isolated Feed System

As mentioned above, once it was determined by both analyses and tests that the motor and feed system were interacting to produce the observed oscillations, a cavitating venturi was placed in the feed system upstream of the motor. With this change, the tests in the lower portion of the test logic (Figure 5) were initiated. In particular. it was desired to perform the high-flow-rate, $40-\mathrm{lb} / \mathrm{sec}$ tests with wide-flow injectors since these two conditions would more closely represent the optimal flight configurations.

Test 8 , the first test with a cavitating venturi adjacent to the motor, was conducted at $20 \mathrm{lb} / \mathrm{sec}$ of liquid oxygen. It used an axial flow and fins in the head end. The fins were rotated $30 \mathrm{deg}$ to a location in front of the fuel grain ports (Condition L-7), the condition most likely to produce smooth combustion. The test did produce essentially a smooth combustion. Deviations from the mean pressure were an average of 4 to 6 percent of mean pressure.
Tests 1 through 8 had shown that if the feed system was allowed to couple with the pressure chamber, high-amplitude oscillations could develop. These tests had also demonstrated that. if sufficient isolation between feed system and motor is provided, smooth combustion can then be achieved at any of the flow rates of 10,20 , or $40 \mathrm{lb} / \mathrm{sec}$. The isolation can come from either the injector pressure drop, orifice, or venturi. All of Tests 1 through 8 used axial flow injectors. To move to wide-flow injectors, Test 9 was configured with conditions L-8; the motor operated smoothly under these conditions.

In an IRAD effort separate from this program, Thiokol was producing a flight-like submerged vectoring nozzle and actuator system that could be tested on the 24 -in. motor. It had been previously agreed that this nozzle would be piggybacked on one of the planned tests. and it was desirable to operate the nozzle on a test with conditions of high liquid oxygen flow. With these considerations in mind. a 40-lb/sec condition was used to produce smooth combustion. For Test 10, fins were placed in the vaporization chamber with the 30-deg rotation that located them in front of the fuel grain ports. The test configuration is L-13 (Figure 14) along with the pressure trace for the test. As can be seen from the figure, smooth combustion was achieved.

When venturis were used upstream of the injector (from Test 8 on), popping during motor shutdown was observed. The combination of venturi and purge line location presented the clean purging of oxygen out of the feed system. Test 11 was a short, 5-sec test with the same motor configuration as on Test 10. The purpose was to evaluate a relocation of the nitrogen purge line. The relocation did not solve the problem. but increasing the purge pressure did solve it. 

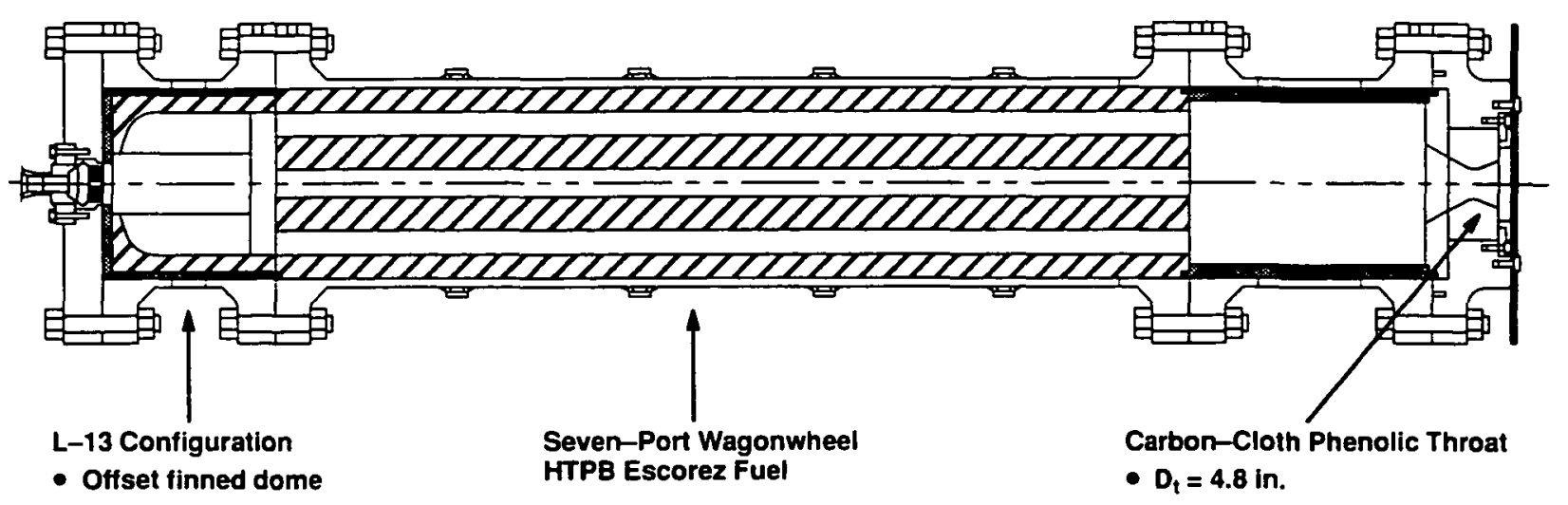

- WH injector

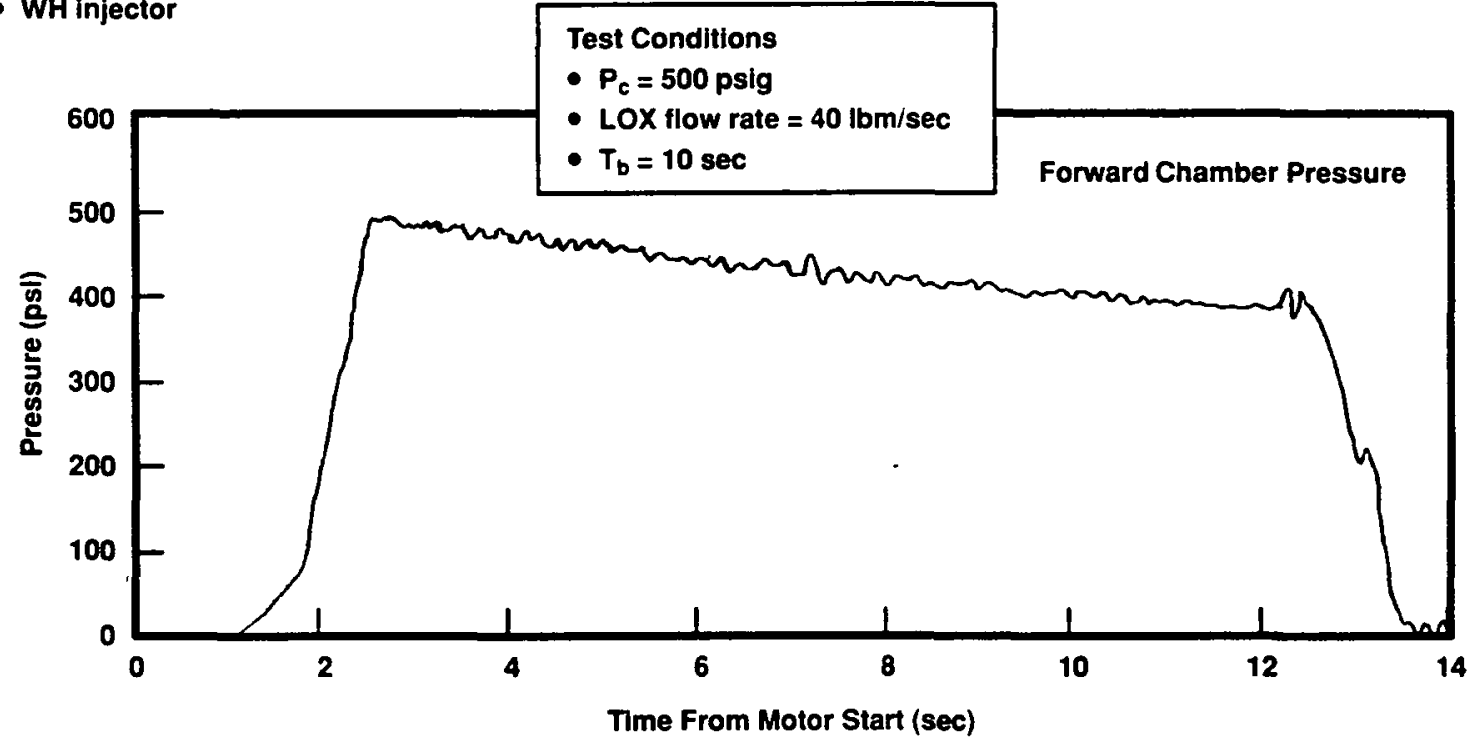

Figure 14. Test 10 Motor Configuration and Pressure Trace

Having achieved smooth combustion with a wideflow injector at $40 \mathrm{lb} / \mathrm{sec}$, the motor was tested with a submerged and vectorable nozzle. This was Test 12 , the last test covered in this paper. The vaporization, chamber, injector, and liquid oxygen flow were all the same as on the previous test. The aft end of the motor was fitted with a new closure to accommodate the submerged nozzle. In addition, samples of various insulations were placed in the aft mixing chamber to determine their performance in a hybrid environment. The test time was set for $20 \mathrm{sec}$, the full duration for the flight motor for which the nozzle was designed. The nozzle duty cycle for the test included 6-deg pitch deflections, 4-deg yaw deflections, and a 4-deg circular rotation.

On the morning of the test, an operator error caused the fire extinguishing system to come on, soaking the power supply for the nozzle actuators. In a recovery effort by test personnel. batteries were requisitioned from cars in the area and the test was performed on schedule. Despite these unpredicted conditions, the motor operated as planned, with smooth combustion for the full 20-sec test duration. The nozzle went through its duty cycle, the only shortfall being that it did not achieve the full 6 deg of motion. A current limiter in the actuator controller prevented the pitch deflection from exceeding $4 \mathrm{deg}$.

Thrust and pressure data showed that performance was consistent with the observed $24 \mathrm{mils} / \mathrm{sec}$ throat erosion. Although acceptable for the silica nozzle being tested, the throat erosion was greater than desired for future systems. More robust throat materials will be evaluated in forthcoming tests.

\section{REMAINING PROGRAM ACTIVITY}

The program is presently 75 percent complete. It has succeeded in its original goal of gaining an engineering understanding and approach to achieving smooth combustion in the 24 -in. motor. At the fundamental phenomenon level, there is still work to be done. In the remainder of the program, motor configuration L-11-wide-flow injector, no fins, and $40 \mathrm{lb} / \mathrm{sec}$ of liquid oxygen (Test 
13) - will be tested to determine the importance of using fins in reducing pressure oscillations in the high-flow tests.

Following Test 13. the motor will be configured with a flight feed system. The system will consist of a flightweight. liquid oxygen tank: a flight valve; and a flight injector. The tank will be located as close to the motor head end as possible; this distance will be no more than a few feet. In addition to the flight feed system. submerged, vectoring flight nozzles will be used on the motor.

Currently, Tests 14 and 15 are planned for this configuration. The first will be a full-duration. constantflow test. The second will be a full-duration test in which the motor is throttled. Prior to these tests. analyses will be performed to determine the likelihood of oscillations arising from a coupling of the flight-like liquid oxygen system and the motor. If oscillations appear probable. a degree of feed system isolation will be obtained with either an injector pressure drop or a venturi.

Also remaining are some 11-in. motor tests to further investigate the effects of conditions in the head end of the motor on pressure oscillations. These tests are currently not definitized. They will take into consideration past 11-in. motor gaseous oxygen tests and the results from a series of $11-$ in. motor liquid oxygen tests that are currently being performed on the JHRAD program with MSFC.

\section{PRELIMINARY OBSERVATIONS -}

Although some important tests and analyses are still to be conducted, tentative observations can be made at this time.
Both testing and analyses have shown the importance of considering the thrust chamber assembly and the feed system as a coupled system for purposes of understanding and eliminating motor pressure oscillations.

The program has demonstrated that smooth combustion can be achieved in multiport grains with flux levels representative of high-performance hybrid boosters.

A consistent observation in all of the motors fired to date is that increased fuel erosion occurs where discontinuities are in the fuel. The 24 -in. motor was intentionally designed to have a cartridge-loaded vaporization chamber distinct from the fuel grain. This feature allows the evaluation of the effects of different vaporization chamber configurations without changing fuel grain. The vaporization chamber fuel butts directly against the main fuel grain. Nevertheless. the slight discontinuity at this joint causes a flow distortion that, during the course of firing, results in higher fuel erosion than in either the rest of the vaporization chamber or the main fuel grain. The increased fuel erosion at this point is the limiting factor in test durations for the 24-in. motor, as it is presently configured.

As far as is known, the tests on this program are the first that have used submerged, movable nozzles on hybrid motors. Nothing was unusual with the submerged nozzle test, indicating that submerged, movable nozzles will be the best way to provide thrust vectoring for hybrid motors. 